\title{
¿Identidad desdibujada? Acerca de la conformación identitaria profesional del diseñador industrial*
}

\author{
María Eugenia Correa*
}

\section{Resumen}

La práctica del Diseño Industrial cuenta en nuestro país con una trayectoria de más de 50 años. Si bien remite a una profesión consolidada, autónoma y altamente relevante en la actualidad, simultáneamente nos conduce a pensar en la propia constitución de los diseñadores como profesionales. Esto, en el marco de una situación ciertamente contradictoria: recibimos una formación al servicio de las empresas, pero al mismo tiempo, estas desconocen esa formación. Este desconocimiento sumado a la diversidad de tareas para las cuales el diseñador industrial se encuentra habilitado complejizan el campo de inserción laboral, resultando en una construcción identitaria profesional ciertamente compleja e imprecisa ante esta diversidad y escasa especificidad de acción.

Este trabajo se orienta a reflexionar acerca de la conformación de la identidad profesional del diseñador industrial. Una figura altamente relevante para la sociedad y la cultura contemporáneas, pero escasamente reconocida como tal.

* Artículo recibido el 27 de junio de 2014. Aceptado el 4 de noviembre de 2014.

* María Eugenia Correa es Socióloga (UBA), Doctora en Ciencias Sociales (UBA) y Magister en Sociología de la Cultura (IDAES-UNSAM). Investigadora asistente de CONICET en el Instituto de Investigaciones Gino Germani de la Facultad de Ciencias Sociales de la UBA.

Correo electrónico: eugeniacorrea@sociales.uba.ar 


\section{Palabras clave}

Diseño industrial - identidad profesional - inserción laboral.

\section{Abstract}

The discipline of Industrial Design has more than 50 years of trajectory in our country. This one, although it belongs to a consolidated, autonomous and highly relevant profession at the present, at the same time it makes us think about the constitution of designers as professionals. This fact is immersed into a certain contradiction: we talk about a formation as a service for the companies, but these, at the same time, ignore them. This unknown situation, in addition to diversity of tasks for what the industrial designer is oriented to do, become complex his labour insertion field, becoming also his own professional identity certainly complex and undefined because of this diversity and this unspecified labour action.

In this sense, this work proposes to reflect on this issue: the conformation of the professional identity of the industrial designer. A highly relevant figure for the society and the contemporary culture, but barely recognised as well.

\section{Keywords}

Industrial design - professional identity - labour insertion.

\section{Introducción}

En los últimos años la actividad del diseño se ha visto altamente incrementada dado su mayor desarrollo en la escena económica local por parte de actores que han apelado a esta área en la conformación de proyectos comerciales y profesionales.

Específicamente, desde el año 2001 numerosos diseñadores y emprendedores han desarrollado proyectos de 'diseño independiente' de indumentaria y objetos en la ciudad de Buenos Aires, dando lugar a una mayor visibilidad de esta práctica cultural orientada a la producción de bienes al servicio de la sociedad y sus necesidades cotidianas.

Con respecto a esto, es importante destacar el contexto que delineó esta nueva configuración productiva del diseño independiente, y específicamente, el crecimiento de la actividad del diseño en los últimos años. Esto es, a partir de la década del 90 en la Argentina, la ampliación de una oferta basada en la diversidad de productos provenientes del exterior incidió en un proceso de reconfiguración de los consumos, generando una apertura en el mercado globalizado hacia elecciones por productos diferenciados, con una impronta estética y singular basada en gustos individualizados. 
Este cambio en la conformación de estilos de vida diferenciados acompañó la gestación de una nueva estética reflejada en los consumos. La puesta en escena de nuevas prácticas culturales alojó a la producción de diseño contemporáneo que comenzó a desplegarse en el mercado en la década de los 90 en la Argentina. Si bien en este período se importaban bienes de diseño producidos en el mercado internacional -un mercado que privilegiaba la investigación y el desarrollo en la producción-, con el tiempo, ya entrado el nuevo milenio, se daría lugar a una recuperación de la producción local, en relación a la cual el diseño comenzó a desempeñar un papel clave tanto en la producción como en el consumo.

Este crecimiento del diseño, del valor agregado al producto, así como el propio surgimiento del 'diseño independiente', son consecuencia no sólo de la valorización por los nuevos consumos mayormente individualizados, que ahora estos diseños 'de autor' se proponían satisfacer, sino también del propio devenir del mercado que integraría la pluralidad de acción de las propias prácticas profesionales.

Es así que en este nuevo contexto, la confección de bienes a partir del desarrollo del diseño en su proceso productivo habría de instalarse en el mercado local, y paulatinamente en los imaginarios sociales, alcanzando esta práctica un mayor protagonismo en el escenario económico y social.

Ahora bien, esta mayor visibilidad del diseño se contrapone en un punto con la cierta invisibilidad o escaso reconocimiento que presentan los diseñadores al momento de integrarse al espacio para el cual los mismos han sido formados es decir al ámbito industrial. Es al interior de este sector donde estos trabajadores deberían desarrollarse profesionalmente, añadiendo valor a los productos, así como mayor competitividad e innovación.

Pero la situación que actualmente predomina en relación a la integración de estos profesionales en las empresas es ciertamente contradictoria, dado que si bien se encuentran formados para desempañarse en la producción industrial, al mismo tiempo, son escasas las empresas que buscan contar con diseñadores industriales en su plantel, generando, en la mayoría de los casos, una inserción de tipo independiente.

De este modo, la escasa participación de diseñadores industriales al interior de este sector supone una revisión de su propia función y del rol que ocupa este actor en la escena económica y productiva al servicio de la comunidad.

Este trabajo busca, en este sentido, reflexionar en torno a estas cuestiones, y tratar de dar respuesta a ciertos interrogantes, entre otros: ¿Cómo se configura actualmente el desempeño profesional del diseñador industrial? ¿Cuál es su relación con la industria y con la producción de bienes industriales? ¿Cómo incide esta mayor o menor integración al interior de la industria en el desarrollo de su propia identidad profesional? 
Trataremos de dar cuenta de estos cuestionamientos -escasamente abordados desde las ciencias sociales- buscando reflexionar en torno a esta figura, ciertamente relevante en la producción de la cotidianidad de la sociedad contemporánea. Una figura cuya construcción identitaria deviene ciertamente compleja a la luz de su modalidad de inserción en la escena económica local.

\section{El diseño como práctica proyectual}

Antes de comenzar a analizar la figura del diseñador industrial, su configuración laboral y productiva y su vinculación con el sector industrial, es preciso definir previamente el término diseño, esto es, qué comprendemos por dicha actividad, cuál es su área o áreas de incumbencia y espacios de acción.

Para tanto, y para delimitar específicamente las funciones de esta práctica, debemos remontarnos a los orígenes del diseño, lo cual implica situarnos en la consolidación del período de industrialización, hacia el siglo XIX en Europa, en torno a un nuevo paradigma productivo asentado en la lógica capitalista.

Los bienes manufacturados, que eran realizados anteriormente por artesanos, ahora eran producto de la máquina industrial, la cual, si bien buscaba abastecer un mercado en crecimiento, no garantizaba completamente la calidad de la producción. Ante esta realidad, con el arribo del diseñador -que inicialmente se trataría de una transición del artista-artesano hacia el diseñador, figura que es más claramente visible en la época de la Bauhaus, a comienzos del siglo XX en Alemania- se buscó incorporar a la producción una mayor articulación entre los elementos tecnológicos, estéticos, simbólicos y técnicos que integraban este proceso. De esto se trataría la idea misma de la 'proyección' -o "proyectación", tal como la plantea el artista y diseñador Tomás Maldonado- concebida en torno a la práctica misma de diseñar.

De este modo, tal como afirma Maldonado, "proyectar la forma significa coordinar, integrar, y articular todos aquellos factores que, de una manera o de otra, participan en el proceso constitutivo de la forma del producto" (1993: 12), esto es, comprender el diseño en tanto proyectación de una forma, desarrollar su ideación hasta volverla un producto con una forma y función determinadas, participando activamente en el proceso de su producción y evaluando atentamente el desarrollo global de este proceso.

En este sentido es que se puede pensar el rol del diseñador -específicamente del diseñador industrial- en términos de "coordinador", puesto que:

Su responsabilidad será coordinar, en estrecha colaboración con un gran número de especialistas, los requerimientos más variados de la fabricación y del uso de productos; la responsabilidad final por el logro de la máxima productividad en la fabricación y la máxima satisfacción material y cultural del consumidor será suya. (Maldonado, 2003: 6) 
De esta manera, se concebía al diseñador en función de una destacada participación en la industria, en los procesos de producción de bienes, a partir de una coordinación e integración de los elementos necesarios para llevar a cabo satisfactoriamente la fabricación de un producto, y posteriormente dar cuenta de un eficiente desarrollo utilitario.

En esta misma concepción entraba en juego la idea del diseñador orientado a generar productos con calidad industrial, funcionales, durables, con atractivo estético, una combinación de factores que otorgasen satisfacción al usuario. En este sentido, tal como plantea Aquiles Gay:

En el Diseño Industrial se plantea la necesidad de conciliar los aspectos técnicos y los estéticos. Los factores estéticos están vinculados con la forma, el color, el tratamiento de las superficies, etc., es decir con todo lo que pone en relación el objeto con los diversos sentidos del hombre, la vista, el tacto, etc. Por otra parte, en todo objeto, equipamiento, máquina, vehículo, etc. hay que tener en cuenta también su robustez, simplicidad de uso, economía, y además la sensación que produce (gusta, o no gusta); no basta que el objeto cumpla su función de uso, que sea robusto, simple y económico, sino también que su forma resulte agradable, muchas veces novedosa y en general funcional con relación a las características utilitarias del producto para lograr que el objeto sea placentero. (Gay, 2004: 12)

De este modo, el rol fundamental del diseñador industrial se encuentra orientado a articular lo relativo a la técnica con la estética, a alcanzar una forma y una función determinadas que vuelvan al producto un elemento utilitario, eficaz, y al mismo tiempo generador de placer y disfrute en quien lo utiliza. Al desarrollar el producto, también es fundamental la ergonomía, puesto que el diseño ergonómico permite una mayor usabilidad de los artefactos producidos, mejorando su eficiencia en el uso y una mayor productividad, al integrarse los diseños a las necesidades de los usuarios.

Este proceso de diseño está inscripto en un contexto social que permite generar cierto tipo de productos, con características propias del período, espacio, tiempo en el que se produce. Así, toda la actividad del diseño se proyecta en función de la cotidianidad en la que surgen las ideas, hacia la que está orientada esta proyección, y materializada esta creación.

Es decir que el diseño, en tanto actividad orientada a la producción de bienes, asume las dimensiones económicas, sociales y culturales que se proyectan en todo objeto creado. Con ese criterio, Ledesma plantea que "el diseño es una actividad de proyección en un doble sentido: se proyecta internamente sobre la obra a partir de sistemas semióticos que le son propios, y en esa proyección, proyecta un tipo de relaciones sociales" (Ledesma, 2005: 33). Es decir que el diseño en sí mismo atañe una 
intervención en lo social, configura su producción al interior de un contexto sociocultural que incorpora cambios, y en este proceso interviene la práctica de diseñar, configurando modos de hacer, de presentar los objetos, adaptados al nuevo contexto. En esta misma línea, Otl Aicher afirma que "el diseño consiste en adecuar los productos a la circunstancia a que están adscritos. Y esto significa sobre todo adaptarlos a circunstancias nuevas. En un mundo que cambia, también los productos tienen que cambiar" (Aicher, 1994: 18).

El diseño atraviesa de este modo la cultura de una sociedad, en el sentido que construye objetos en tanto bienes culturales, constituidos como significantes propios de esa cultura. Así, al intervenir el diseño en la sociedad, en el desarrollo productivo de los bienes a ser creados y materializados, configura procesos que permiten una mayor y más equilibrada productividad, atendiendo a un uso racional de los materiales, a la innovación en términos productivos, y al desarrollo y la elaboración eficientes en términos de calidad y funcionalidad de los objetos.

Ahora bien, la destacada participación que tiene el diseñador en la cultura y en la sociedad dada su capacidad para comprender los cambios culturales y materializarlos en bienes creados debe ser comprendida a la luz de su activo rol en su medio, pero sobre todo, buscando analizar la modalidad de su intervención en la estructura productiva.

\section{Constitución de la profesión al interior de un campo complejo}

El campo del diseño, específicamente del diseño industrial, orientado a la proyección y producción de objetos de uso cotidiano, se presenta desde sus orígenes como un espacio de entrecruzamiento de saberes y discursos diversos forjadores de la identidad profesional del diseñador industrial.

En este sentido, este campo se ha conformado a la luz de los lineamientos de otros campos proyectuales, como son el del arte y la arquitectura moderna, sedimentando sentidos diversos acerca de la realidad sobre la cual operan. Tal como expresa el diseñador Gui Bonsiepe, el campo del arte atravesó históricamente el accionar del diseño, volviéndolo una práctica con escaso arraigo en la economía y la industria, lo cual en cierto modo ha afectado la concepción productiva del diseño al servicio de la sociedad:

Cierto, existe la historia del arte, que se asignó la función de ocuparse marginalmente también de la historia del diseño. Pero la limitación de la historia del arte consiste en la tendencia de tratar al diseño y sus manifestaciones principal y hasta exclusivamente como un fenómeno estético-visual y nunca como fenómeno arraigado en la industria, en las empresas, en la economía y en las políticas de desarrollo tecnológico y social. El diseño es una realidad con un grado de complejidad que va mucho más allá de un mero hecho de estilo. (Bonsiepe, 2008:

10) 
En una línea semejante, Aquiles Gay sostiene este distanciamiento necesario entre arte y diseño, al plantear que:

Esta nueva actividad profesional, el Diseño Industrial, si bien está enmarcada por la estética, no pertenece al campo del arte, sino de la tecnología, su actividad no consiste (como sucedía antes) en embellecer los productos agregándoles ornamentos que nada tienen que ver con su funcionalidad, sino más bien en lograr una unidad entre tecnología y estética en la misma etapa de concepción del producto, para lograr que el objeto, además de ser funcional, sea agradable a la vista. (Gay, 2007: 11)

El accionar del diseño difiere claramente del propio del arte, así como las funciones que lleva adelante todo diseñador al buscar satisfacer al usuario en su vida cotidiana no se corresponden con las del artista. Pero desde los orígenes del diseño la labor del artista-artesano ha tenido una mentada articulación con la del diseñador, podemos decir, sin dudas, que hasta hoy se concibe el diseño como una práctica claramente influenciada por el campo del arte. Ante esto, Bonsiepe plantea lo siguiente:

Sin querer subestimar los aportes provenientes de las artes visuales y de la arquitectura moderna para el desarrollo del diseño industrial y comunicacional, hoy en día estas dos disciplinas del diseño han ganado autonomía suficiente, con cuerpos de saberes propios, para no depender más de una tutela. En comparación con la arquitectura enfocan realidades diferentes. En comparación con las artes enfocan la realidad de manera distinta, concentrándose en la calidad de uso de los objetos e informaciones en las diferentes áreas de la vida cotidiana: trabajo en el campo, en la industria, en la oficina, en el tráfico, transporte, en los hospitales, educación, deporte, turismo, casa y hasta la mera supervivencia de los grupos sociales excluidos por el actual modelo económico-social. (Bonsiepe, 2008: 10)

Es así que, si bien ambos campos, tanto el del arte como el del diseño industrial, han confluido en los inicios de esta práctica, recibiendo el diseñador influencias del artistaartesano, con el tiempo, el recorrido construido por la disciplina del diseño ha permitido configurar un campo autónomo, como menciona Bonsiepe, con cuerpos de saberes propios, en cuyo seno se delinea la figura del diseñador industrial.

Pero dicho campo, en su propio devenir, se ha construido, y se construye, no sin conflictos mediante, los cuales atraviesan la constitución de la figura del diseñador: su inserción, su definición, su propia construcción identitaria.

Analizaremos a continuación esta cuestión. 


\section{La encrucijada del diseñador: entre la concepción industrial o la realidad múltiple}

Como hemos planteado anteriormente, la disciplina del diseño se encuentra atravesada por múltiples discursos, saberes y prácticas, emanados de las influencias de los campos proyectuales que han atravesado su conformación: el arte y la arquitectura. Al mismo tiempo, los propios discursos performadores de la orientación de este profesional se articulan en un abanico que integra aquellos de carácter más 'tradicionalistas', de tipo industrialistas, con aquellos más vinculados a una multiplicidad de acciones en las cuales desempeñarse.

Así, esta diversidad de acciones se contrapone a la mentada unicidad a la que aspira la formación universitaria al privilegiar la inserción en el desarrollo de producto industrial (Correa, 2012). De este modo, la inserción del diseñador en el escenario productivo refleja la complejidad que dicha figura porta en su propia constitución, al dar cuenta de un universo discursivo performativo no unívoco en cuanto a su inserción y desempeño profesional.

De esta manera, al indagar en los discursos predominantes en torno a estos dos sentidos presentes en la orientación del diseñador, podemos observar, por un lado como hemos mencionado anteriormente- una mirada de corte 'industrialista', en relación a la cual se evidencia cierta línea de pensamiento, a saber:

Es en la industria de la producción donde se desarrolla con amplitud el ejercicio de la profesión. En este sentido la relación entre las empresas de producción y la carrera de DI es necesaria y sinérgica. No es imposible, pero sí muy complejo hacer que un estudiante de la carrera pueda entender de los procesos productivos, de la transformación de las materias primas, de los tratamientos superficiales, de los procesos de ensamblaje, del embalaje, en fin, de la logística de una cadena de producción, sin haberlo visto y se lo hayan explicado. La relación debería ser intensa, y tendría como valor agregado el conocimiento por parte de la empresa de las características de la profesión, sin duda útil para una mejor comprensión y relación entre diseñadores y empresarios. (Entrevista al diseñador industrial Hugo Kogan) ${ }^{1}$

Por otro lado, aquel planteo orientado a promover la diversidad en la inserción laboral respondería a la construcción de un perfil profesional de tipo 'múltiple', mayormente adaptado a las necesidades diversas del mercado. En este sentido, a partir de la realización de diferentes entrevistas, obtuvimos los siguientes testimonios, en línea con este segundo discurso en torno a la figura del diseñador:

1 Fuente: Otro lado. Periódico de la Facultad de Arquitectura, Diseño y Urbanismo de la Universidad de Buenos Aires. www.fadu.uba.ar/sitios/otrolado/imagenes/per-04.pdf 
Es que [el Diseño Industrial] no es para la industria. Es hacer una lectura... O sea en el origen tiene que ver con eso, ahora lo que termina pasando, y mismo lo que hoy está pasando y que repercute también en la formación y la inserción laboral, es que estamos pensando más en cuestiones culturales que en cuestiones productivas. (...) [El diseñador] toma las cuestiones culturales en que vive $y$ en base a eso cristaliza un objeto que sea funcional a toda esta complejidad de cosas. Eso es lo que hace un diseñador industrial. Después puede hacer desde un cierre de una campera, puede hacer un teléfono, una zapatilla. Es un catalizador de lo que está pasando en determinado momento $y$ donde hay una impronta personal de cierta sensibilidad donde casi es una vía expresiva artística de cada diseñador que uno le da bajada, que es su visión en determinado momento que está viviendo (...) A mí me parece que el diseño industrial tiene que ver necesariamente con esto de lo diverso, no exclusivamente restringido a lo que es la industria como cierto sistema de producción. No diría la industria... Tenés miles de cosas que tienen que ver con el consumo, con el consumo de bienes culturales, con la cultura, con manifestaciones artísticas, entonces me parece que ahí es lo interesante. Lo que a mí me parece interesante de la disciplina y lo que me llena tanto para estar acá en la facultad o cuando estoy en el estudio con un proyecto" (Mario, diseñador industrial, trabaja en forma independiente). ${ }^{2}$

Ante esta realidad asentada en visiones claramente divididas, observamos que aquello que se vulnera y se confronta es la propia subjetividad de este trabajador, cuestionando, así, su identidad profesional. La diversidad de acción o la inserción industrial 'acorde' a la orientación tradicional de la profesión, devienen elementos constitutivos de la propia conformación del diseñador como profesional. ¿Pero qué ocurre cuando estos elementos integradores, performadores de la propia identidad, se desencuentran con la realidad?

En relación al frecuente desencuentro entre lo que se enseña en la facultad y aquello que uno realiza en su desempeño laboral, un entrevistado expresa lo siguiente:

...una cosa es lo que a uno le enseñan, otra cosa es lo que termina haciendo, entonces si es tan diferente hay que tratar de coordinarlo para que los diseñadores aprendan lo que van a hacer después por lo menos, o ver qué es lo que pide el mercado, a ver si

\footnotetext{
2 Estas entrevistas forman parte de la investigación desarrollada en el marco de la tesis doctoral, para la cual se ha estudiado la inserción laboral de los diseñadores industriales egresados de la Universidad de Buenos Aires. Se han realizado en este marco 25 entrevistas en profundidad a diseñadores provenientes de la carrera de Diseño Industrial de la Facultad de Arquitectura, Diseño y Urbanismo de la UBA. Cabe destacar que este estudio fue de carácter cualitativo, buscando privilegiar el interés por las perspectivas, experiencias y relatos de los propios entrevistados en relación a sus inserciones y desempeños profesionales, con lo cual se manifiesta cierta complejidad al momento de buscar dimensionar este fenómeno y de establecer magnitudes. Igualmente, es de destacar que este ha alcanzado mayor relevancia en la última década dado el incremento de estudiantes de carreras de Diseño -tanto en Buenos Aires como en otras ciudades del país-, así como de profesionales de esta disciplina insertos en el mercado, en mayor medida provenientes de Diseño de Indumentaria y Textil, de Diseño Gráfico, y en menor medida, de Diseño Industrial, siendo estos un núcleo más reducido de profesionales.
} 
dentro de lo que pide el mercado les gusta algo y se pueden dedicar a eso. Y no salir con unos humos porque hacen... en la facultad los trabajos es de diseñar computadoras, diseñás electrodomésticos, y después para diseñar en la vida real es imposible, no sé cuánta gente diseña electrodomésticos en este país, deben ser cinco diseñadores (Santiago, diseñador industrial, trabaja en empresa).

La mayor o menor integración del egresado en el mercado, en espacios de incumbencia profesional, de desarrollos acordes a la orientación 'tradicional' promulgada por la universidad genera situaciones de satisfacción -o frustración- con respecto a la labor realizada. La dificultad de insertarse en espacios 'tradicionales' planteada por el entrevistado, muchas veces se vincula a la propia indefinición de acuerdo a lo esperable de este profesional. ¿Qué se espera de él? ¿Se espera que participe en la industria? ¿Que quede por fuera de ella? ¿Que establezca una inserción 'múltiple'? Esta cuestión acerca de la mayor o menor especificidad esperada, o encontrada en el mercado a la hora de insertarse se corresponde con la indefinición que portan estos profesionales como parte de la formación obtenida. El entrecruzamiento de discursos performadores que orientan al diseñador en un camino plural de acción se articula con un escenario de inserción que parece desconocer la especificidad de este profesional: su desempeño en la industria. Ante esto, diseñadores entrevistados expresan que:

...Sigue siendo medio desconocido [el trabajo del diseñador industrial]. Por un lado es una carrera bastante nueva y por otro lado porque tampoco es algo tan definido. $O$ sea no es que... un diseñador gráfico es bastante obvio lo que puede llegar a hacer, más allá que hacen más cosas de las que uno cree. Pero a priori vos sabés para qué te puede servir, si querés hacer un logo para una empresa sabés que tenés que llamar a un diseñador gráfico. Ahora ¿por qué tengo que llamar a un diseñador industrial? Y, alguna gente sabe, pero no todos. Ni siquiera el dueño de una empresa sabe bien. [...] Entonces me parece a mí que ante esa duda se contrata, no sé, a un ingeniero o algo del estilo (Joaquín, diseñador industrial, trabaja en estudio independiente).

...La industria no conoce el diseño industrial... No saben lo que es el diseño industrial, no saben para qué sirve y no le dan el espacio. Finalmente todo lo que es diseño lo resuelven de otra manera, no con un diseñador. Con lo cual en general logran pobreza en la forma y dificultad en la concreción. Yo cuando estaba en el estudio tanteé unas cuantas empresas, después tuve entrevistas con varias y eso era lo que más se veía. $Y$ en algunas sí había diseñadores industriales, pero como el desarrollo de nuevos productos era escaso, cuando los realizaban por ahí tercerizaban a alguien. Pero te estoy hablando de eso ya hace tiempo, así que no sé hoy por hoy cómo está planteado. Me parece que sigue habiendo un divorcio, bah, un desconocimiento entre 
lo que es industria y lo que es diseñador industrial $y$, que es una verdadera lástima (Julián, diseñador industrial, trabaja en empresa).

Con respecto a esto, la situación que actualmente predomina en relación a la integración de estos profesionales en las empresas es ciertamente contradictoria, dado que si bien ellos se encuentran formados para desempañarse en la producción industrial, al mismo tiempo, son escasas las empresas que buscan incorporar diseñadores industriales a su producción. Esto puede atribuirse a cierto desconocimiento acerca de su idoneidad, sumado a la escasez de experiencia que presentan con respecto a la labor a desarrollar. Esto da como resultado una escasez de diseñadores insertos en empresas, lo cual conduce a dos instancias. Por un lado, la elección, por parte de una mayoría de diseñadores industriales, de desarrollarse de forma independiente en su desempeño laboral, y por otro, vinculado a lo anterior, cierto 'desdibujamiento' de su propia identidad profesional, al desempeñarse en formatos más de tipo artesanales que industriales, y al orientarse a espacios reducidos de inserción, en clara contraposición con el planteamiento del diseño moderno. Este postula la acción del diseñador al servicio de la sociedad, concibiendo bienes que permitan el amplio acceso a un estado de mayor bienestar y calidad de vida.

Es importante destacar que se está intentando revertir esta situación de escasa integración de diseñadores en la industria y que, paulatinamente, se están incorporando diseñadores a las empresas o se incorpora servicio de diseño a éstas, en gran medida a partir del desarrollo de los programas oficiales, tanto del gobierno de la Ciudad de Buenos Aires como de la Nación, de gestión de diseño. A través de estos programas se busca incorporar este servicio a la actividad de las empresas dedicadas a la producción de bienes (indumentaria, accesorios, objetos, mobiliario, entre otros), y, en los últimos años, han promovido la inclusión de este servicio en numerosas PyMES, obteniendo en varios casos resultados altamente positivos. ${ }^{3}$

\section{¿Identidad diluida? ¿O un nuevo modo de configuración identitaria no industrial?}

Ahora bien, tal como se mencionó anteriormente, los diversos saberes en interrelación que delinean la formación del diseñador, sumado a la indefinición en torno a la orientación de la profesión -en el sentido de la amplitud del campo de acción sobre el cual puede operar-, dan lugar a una inespecificidad en los términos de la inserción de este profesional.

\footnotetext{
3 La incorporación de diseño en empresas y su impacto en ellas ha sido abordada por el Centro Metropolitano de Diseño de la ciudad de Buenos Aires, a través de sus programas. Esto puede observarse en la publicación "Aportes del diseño. Una herramienta para mejorar el desempeño empresarial", un estudio de corte cualitativo, complementado con el trabajo de índole cuantitativa, denominado "PyME + Diseño. Un estudio de la demanda de diseño entre las PyME del Área Metropolitana de la Ciudad de Buenos Aires", realizado conjuntamente con el Observatorio de Industrias Creativas del Gobierno de la Ciudad de Buenos Aires y la Fundación Observatorio PyME.
} 
En relación a esto, podemos interrogarnos acerca de cómo concebir la propia identidad profesional ante un escenario de formación e inserción diversa. Esto es, ¿cómo pensar una identidad consolidada ante una 'fragmentación' de la labor profesional? ¿Cómo concebirla ante la diversidad e indefinición de la propia formación?

A su vez, el reconocimiento del otro incide en esta cuestión aportando una mirada difusa, puesto que en el ámbito en el que estos trabajadores deberían insertarse, -tal como hemos mencionado para el caso de la industria- no los conocen, ni los reconocen como actores clave para este sector.

Es decir que la posibilidad de darse una identidad, en sentido bourdeano, se ve desdibujada. Esto ocurre, por un lado, como consecuencia de la limitación de integrarse al espacio tradicional de inserción legitimada, y por otro, como efecto de la multiplicidad de acciones en las cuales puede desarrollarse, lo que vuelve a este profesional una figura compleja, dotada de una ambivalencia cuyo reconocimiento se complejiza también. Con respecto a esto, una entrevistada plantea lo siguiente:

...Cuesta o por ahí no está como ya trazado el camino, ¿no? Esto que decía, que por ahí hay como una falta de conocimiento, y entonces... Digo, entre la demanda y lo que nosotros hacemos hay por ahí un hueco. O sea, lo de la oferta es muy diversa, que lo hace muy difícil disfrazar a alguien de diseñador industrial y decir "bueno, éste es nuestro representante", ¿no? "Esto nos representa". Porque en realidad hay gente que es... Produce sus propios diseños y los vende en lugares como, digamos, donde se valora el valor estético que tiene el producto y demás, y otras que trabajan en una metalúrgica mejorando la... Digamos, mucho más cercanos a la Ingeniería. Nos definimos mucho también en función de a qué nos acercamos, ¿no? Que estén más cerca de un trabajo más de Ingeniería o más de Arquitectura o... Yo, por ejemplo, últimamente estoy mucho más vinculada al rubro de lo que es como de moda e indumentaria que industrial propiamente dicho (Sandra, diseñadora en estudio independiente).

En este pasaje se observa la dificultad de 'visibilizar' la figura nítida del diseñador, lo cual se ve reflejado cuando la entrevistada plantea que "se hace difícil disfrazar a alguien de diseñador", dejando en claro que no tiene un rol definido. Pero, ante esto, es preciso reflexionar sobre la propia constitución identitaria, dado su carácter polifónico, en cuanto a los discursos múltiples sobre los cuales ésta se construye:

Existe todo un abanico de discursos interpelantes que materializan actos permanentes de atribución a los sujetos. [...] Debido a la multiplicidad de interpelaciones, la identidad no se compone de identificaciones armónicas; está interceptada por prácticas y discursos diferentes o antagónicos (Longo, 2003: 6). 
La identidad profesional, en este sentido, se construye no sin conflicto mediante, dada la articulación de elementos diversos que la componen, a partir de una propia definición de sí mismo y del otro, al interior de una trama de capacidades, competencias, habilidades, trayectorias en juego. Esta construcción identitaria que define al diseñador se elabora en función del sí mismo, así como del reconocimiento del otro, de componentes subjetivos y objetivos que atraviesan la trayectoria del individuo, su instancia biográfica.

En este sentido, Dubar sostiene que:

La identidad profesional dependerá de la definición desde sí mismo y desde la otredad en cuanto a componentes como las competencias, el estatus, la carrera posible, la construcción de proyectos y las aspiraciones. Este ejercicio construirá una "identidad profesional de base" que permitirá una proyección de sí para el porvenir y que por lo tanto orientará la trayectoria de empleo y la lógica de aprendizaje o formación. Es decir, tal como señala Dubar, que "no se trata sólo de elegir un oficio o profesión o de obtener un diploma, sino de la construcción personal de una estrategia identitaria que pone en juego la imagen del $Y_{0}$, la apreciación de capacidades y la realización de deseos" (Dubar, 2000, en Machuca Barbosa, 2008: 53).

En una línea semejante, Battistini, da cuenta de la dificultad de definir y delimitar la figura identitaria, y, retomando la noción de identidad de Cuche (2001), expresa lo siguiente:

Nuestros tiempos muestran, cada vez con mayor crudeza, la complejidad creciente de nuestras sociedades. Si la identidad es una construcción social, dicha complejidad, entonces, no puede serle ajena. Ningún grupo ni individuo está encerrado a priori en una identidad unidimensional. Es precisamente su carácter fluctuante lo que hace que se preste a diversas interpretaciones. La identidad resulta difícil de delimitar y definir debido a su carácter multidimensional y dinámico. Esto es lo que le confiere su complejidad, pero es lo que le da flexibilidad. La identidad conoce así variaciones, se presta a reformulaciones y también a manipulaciones. (Cuche, 2001: 91-92, en Battistini, 2009: 2)

La propia construcción identitaria del diseñador industrial se ve atravesada por múltiples configuraciones discursivas y prácticas diversas, las cuales, o bien fragmentan y desdibujan su especificidad y configuración profesional, o bien consolidan su figura y su inserción laboral en términos más amplios, más diversos e integradores, adaptados a los requerimientos de un mercado en constante cambio. 
Ambas posibilidades dan cuenta de la realidad que sustenta y atraviesa la formación e inserción laboral del diseñador industrial, de su ambivalente figura e identidad profesional. La construcción de la identidad deviene entonces reflejo de saberes interrelacionados y de prácticas diversas que delinean espacios subjetivos no unívocos de acción. En este sentido, pensar al diseñador de hoy por fuera de la multiplicidad de acciones remite sin dudas a concebir de manera inacabada la pluralidad de operaciones que puede hacer y para las cuales fue formado. Una de ellas es sin dudas la central, el espacio de incumbencia tradicional de acción: la industria. Reconocer esta pluralidad de acciones e identificaciones desde sí mismos, esto es, identificarse con cada uno de estos espacios para los cuales los diseñadores son formados deberá articularse con un mayor reconocimiento de los otros (clientes, industriales, sociedad en general) con respecto a su especificidad vinculada no a una, sino a varias tareas posibles en las cuales desempeñarse. Pero concibiendo -y en esto consiste el desafío- el ámbito empresarial, industrial, como aquel para el cual resultan ciertamente capaces, idóneos, cuya productividad los diseñadores pueden asumir dada la capitalización de conocimientos que poseen para tal fin. La suma de experiencia en este sentido los podrá posicionar en un lugar de mayor reconocimiento a fin de alcanzar una mayor integración a este sistema.

El reconocimiento social de la identidad profesional en términos específicos, pero al interior de un universo plural y diverso se vuelve, entonces, una meta colectiva a alcanzar.

\section{Conclusiones}

A lo largo de este trabajo se ha buscado indagar acerca de la constitución de la figura profesional del diseñador industrial. Hemos observado que esta figura se compone de diversos saberes que delinean su formación y orientación profesional. Esta cuestión sin dudas presenta una incidencia en el modo de concebir a este actor en el escenario laboral, transformándolo en un profesional cuya inserción específica se vuelve difusa, indefinida.

Ante esto, las dudas que nos surgen son: ¿Cuál sería su orientación, su espacio delimitado, preciso, de acción? ¿Cómo construirse una identidad profesional consolidada en un marco de indefinición?

Encontramos, además, una cierta contradicción, que impacta con mayor énfasis en el escenario visible de inserción: la situación de encontrarse orientado, formado hacia un desempeño industrial, pero que, al mismo tiempo, las empresas desconocen. Una cuestión que pone en evidencia las falencias propias del campo. Falencias de la formación o de la modalidad de inserción, orientada en la mayoría de los casos a desarrollos de tipo independientes, lo que genera una debilitada construcción de visibilidad, lazos y reconocimiento en la escena productiva, sea en relación a las empresas o sea en relación a la sociedad, para la cual, finalmente trabajan. 
Estos dilemas que atraviesan a esta figura nos conducen a comprenderla entonces al interior de un campo de construcción disciplinar complejo, con interrelaciones, competencias disímiles, acervos variados de conocimientos que apelan a inserciones diferenciadas. La identidad que resulta de este proceso performativo, discursivo y praxístico, se vuelve compleja en términos de asimilarla, vincularla a áreas específicas de acción.

Pero esto, antes de recrear una situación obstaculizadora para su desarrollo profesional, puede plantear un escenario altamente beneficioso. Los mismos diseñadores comprenden su formación como una caja de herramientas que les permite operar, delinear, proyectar en situaciones diversas. Así, el incorporar un múltiple contenido pasa a ser internalizado como una dimensión positiva. Pero, ante esto, dos instancias deben ser fortalecidas a fin de poder construir un mayor reconocimiento en función de asumir una identidad profesional vinculada a la pluralidad en términos de inserción.

Por un lado, debe superarse la indefinición vinculada a la inserción profesional, arraigada en la clara orientación a la cual deben responder: es decir, la industrial. Por otro lado, es necesario superar el escaso conocimiento al interior de este sector, aquel para el cual históricamente han sido concebidos.

Ambas instancias deben ser incorporadas en un sentido de fortalecer su configuración profesional redefiniendo la orientación impartida, asumiendo sus vastos requerimientos en concordancia con las nuevas demandas del mercado, y apelando a un reconocimiento social, que permita una mayor integración al ámbito empresarial.

Finalmente, la labor del profesional implica un espíritu de adaptación a los cambios, como postulaba Aicher, ante lo cual su figura debe integrarse a la diversidad, a los múltiples espacios de inserción y, en función de ello, el reconocimiento social devendría de la propia visibilidad, integración al sistema productivo y de la propia dotación de sentido identitario.

El 'darse una identidad', en sentido bourdeano, al interior del espacio social es el resultado de un devenir múltiple y complejo, de una construcción no sin conflictos mediante, un proceso dotado de identificaciones diversas que conlleva reflexividad y auto creación, en este caso, para una figura profesional ciertamente relevante, significativa y con un alcance cada vez mayor en la sociedad contemporánea.

\section{Bibliografía}

Aicher, O. (1994). El mundo como proyecto. Barcelona: Editorial Gustavo Gili.

Battistini, O. (2009) Ser estable: ¿una necesidad en las construcciones identitarias? En Battistini, O., Bialakowsky, A., Busso, M. y Costa, M.I. (Comps.) Los trabajadores en la nueva época capitalista. Entre el ser y el saber. Buenos Aires: Teseo. 
Correa, M. E. (2012) Entre la industria y la autogestión. Análisis de la inserción laboral de los diseñadores industriales egresados de la Universidad de Buenos Aires. (19902010). Tesis de Doctorado no publicada. Buenos Aires: Facultad de Ciencias Sociales, Universidad de Buenos Aires.

Cuche, D. (1999). Cultura e identidad. En Cuche, D. La noción de cultura en las ciencias sociales. Buenos Aires: Nueva visión.

Fernández, S. y Bonsiepe, G. (Coord.). (2008). Historia del diseño en América Latina y el Caribe. San Pablo: Blücher.

Gay, A. y Samar, L. (2004). El diseño industrial en la historia. Córdoba: Tec.

Ledesma, M. (2005). Diseño Gráfico ¿un orden necesario? En Arfuch, L., Chaves, N. y Ledesma, M. Diseño y comunicación. Teorías y enfoques críticos. (pp. 15-90). Buenos Aires: Paidós.

Longo, M.E. (2003) Los trabajadores y el trabajo en la crisis. 6to Congreso Nacional de Estudios del Trabajo. ASET (Asociación Argentina de Especialistas en Estudios del Trabajo). Buenos Aires. [On line] Disponible en:

http://www.aset.org.ar/congresos/6/archivosPDF/grupoTematico04/023.pdf

Machuca Barbosa, A. E. (2008) La identidad profesional de los sociólogos. Tesis de Maestría en Ciencias Sociales. FLACSO. México, D. F. Disponible en:

http://conocimientoabierto.flacso.edu.mx/medios/tesis/machuca ae.pdf

Maldonado, T. (1993). El Diseño Industrial reconsiderado. Barcelona: Gustavo Gili.

Rinker, D. (2003). El diseño de productos no es arte - El aporte de Tomás Maldonado al surgimiento de un nuevo perfil profesional. En Modelos de Ulm. Hochschule für Gestaltung Ulm 1953-1968. Ulmer Museum. Instituto para las Relaciones con el Extranjero (IfA). 